\title{
Cognitive and Collaborative Demands of Freight Conductor Activities Results and Implications of a Cognitive Task Analysis
}

\author{
Hadar Rosenhand ${ }^{1}$, Emilie Roth ${ }^{2}$, Jordan Multer ${ }^{1}$ \\ ${ }^{1}$ Volpe National Transportation Systems Center \\ ${ }^{2}$ Roth Cognitive Engineering
}

\begin{abstract}
This paper reports the results of a cognitive task analysis (CTA) that examined the cognitive and collaborative demands placed on conductors and the knowledge and skills that experienced conductors have developed that enable them to operate safely and efficiently. A secondary aim of the CTA was to understand the implications of the Rail Safety Improvement Act (RSIA) of 2008 on the role of the freight conductor, specifically the mandate for conductor certification and implementation of positive train control (PTC). Data was collected through a combination of field observations, phone interviews and on-site focus groups with experienced conductors, locomotive engineers, trainers, and training managers. A primary finding is that conductors and locomotive engineers operate as a joint cognitive system (Woods and Hollnagel, 2006). They not only participate jointly in monitoring outside the window, they serve to fill-in each other's knowledge gaps, and participate jointly in planning activities, problem-solving, and identifying and mitigating potential risk. The CTA addresses the issue of how new technologies, such as PTC, are likely to impact the role of conductors in the future by laying out the multiple ways in which conductors contribute to safe and efficient train operation and contrasts this with the anticipated features of PTC. The CTA also uncovered a variety of knowledge and skills that distinguish experienced conductors from less experienced ones. These findings suggest an opportunity to potentially accelerate building conductor expertise by providing insight to future training methods.
\end{abstract}

\section{BACKGROUND}

Railroad operations in the United States are undergoing rapid changes. These changes are due in part to the Rail Safety Improvement Act (RSIA) of 2008 which calls for, among other things, conductor certification and the implementation of positive train control (PTC) on applicable freight and passenger rail lines. PTC integrates command, control, communication and information aspects for controlling train movements and is intended to act as a back-up to the locomotive engineer. PTC will automatically stop the train in situations where speed limits or track limits of authority are exceeded so as to prevent train-to-train collisions, over-speed derailments, and casualties to roadway workers.

As part of its efforts to investigate the safety implications of applying emerging technologies (such as PTC) to railroad operations, the Federal Railroad Administration's (FRA) Office of Research and Development sponsored a series of Cognitive Task Analyses (CTA) to examine the cognitive and collaborative demands associated with different railroad operations' positions. The first CTA focused on railroad dispatchers (Roth, Malsch, \& Multer, 2001). A second CTA addressed roadway worker activities (Roth and Multer, 2007). The third CTA focused on locomotive engineers (Roth and Multer, 2007). This paper documents the results of a CTA that was conducted to examine the cognitive and collaborative activities of the freight train conductor.

\section{STUDY OBJECTIVES AND APPROACH}

The purpose of the freight train conductor CTA was to gain an understanding of the role of conductors in today's freight rail operations. The goal was to understand the cognitive and collaborative activities associated with the role of the freight train conductor, the situational factors that arise to complicate performance, and the knowledge and skills that experienced freight train conductors have developed to cope with performance demands so as to maintain safe and efficient operation. A related aim was to understand the implications of the RSIA of 2008 on the role of the conductor, specifically the mandate for conductor certification and implementation of PTC. The goal was to understand current conductor training programs and future training trends to provide insight to the FRA for the conductor certification effort and, to the extent possible, understand and anticipate potential impacts of PTC on the conductor's work.

The CTA focused primarily on the freight train conductor operating on the mainline. Mainline freight train crews operating in the United States generally include two individuals, typically a locomotive engineer and a conductor. The conductor, in broad terms, is in charge of the train, including supervising train operations, safety and efficiency. The locomotive engineer is responsible for running the locomotive.

A CTA analyzes the high-level cognitive and collaborative functions that individuals and teams need to engage in to meet the demands of the work (Roth, 2008; Bisantz and Roth, 2008). The freight train conductor CTA was performed based on a combination of structured interviews with stakeholders in industry, labor and government, interviews and focus groups with conductors, locomotive engineers, conductor trainers, and training managers, and observations at rail yards. 
The CTA adopted a macrocognition perspective that attempts to characterize individual and team cognition at a functional level of description that is most relevant to performance in natural settings (Klein, Ross, Moon, Klein, Hoffman and Hollnagel, 2003; Klein, Moon and Hoffman, 2006; Patterson and Miller, 2010). This contrasts with microcognitive level descriptions that tend to characterize cognitive processes at a more detailed, millisecond time scale, information processing level (Klein, Klein and Klein, 2000).

Macrocognitive functions relevant to human performance in complex, dynamic, high-risk domains include:

- detecting/noticing

- directing attention

- $\quad$ sense-making/understanding

- $\quad$ planning/deciding

- communicating/coordinating (teamwork functions)

- Managing workload

Directing attention and managing workload are often not explicitly listed as macrocognitive functions. They are neverthe-less critical cognitive tasks in dynamic, high risk domains, where domain practitioners are required to determining where to direct attention and focus activity under high workload/ high attention demand conditions (Klein et al., 2003; Klein, 2010; Woods, Dekker, Cook, Johannesen and Sarter, 2010). They were thus included in the macrocognitive analysis framework that guided the conductor CTA.

\section{METHODS}

The CTA was based on several sets of interviews and site visits conducted between January 2009 and April 2010. Interviews and focus groups were conducted among stakeholders and railroad practitioners, experienced conductors, and conductor trainers and training managers, including representatives from the Federal Railroad Administration (FRA), Association of American Railroads (AAR), United Transportation Union (UTU), Transportation Technology Center Inc. (TTCI), the National Academy of Railroad Sciences (NARS), Burlington Northern Santa Fe (BNSF), and Union Pacific (UP). Site visits included a trip to the National Academy of Railroad Sciences (NARS), Union Pacific Beaumont Yard, and Union Pacific Houston Yard.

All interviews were conducted using a set of predefined questions that served as a 'checklist' of topics to be covered. The question sets were not used as a script, therefore actual questions asked and their order varied depending on participant responses.

A total of 17 individuals with experience as conductors and/or locomotive engineers participated in interviews/focus groups. Topics covered included:

- cognitive and collaborative demands associated with different aspects of the conductor's job (e.g., cognitive workload, attention demands, need for vigilance, memory demands, communication and coordination demands, and need for shared situation awareness);
- demands associated with handling unanticipated events/troubleshooting as well as ensuring safety;

- conductor training and perspective on conductor certification;

- perspectives on PTC technology.

Interviews and focus groups lasted between one to two hours and were tape recorded depending on whether or not the participant gave their permission. Interviews were transcribed and analyzed with the goal of identifying recurrent themes across interviews and specific incidents described by the participants that illustrate the themes.

The analysis focused on identifying:

- $\quad$ cognitive and collaborative demands in the current environment that contribute to performance difficulties and errors;

- types of errors that can arise, with an emphasis on errors more likely to occur among less experienced practitioners;

- $\quad$ skills and strategies that experienced practitioners have developed to build and maintain shared situation awareness, to avoid or catch errors, and to improve efficiency and enhance safety.

\section{RESULTS}

\section{Cognitive Tasks and Associated Challenges}

To better understand the cognitive tasks and associated challenges with the freight conductor's job, we broke the freight conductor's job down into five categories:

- Managing the train consist

- Assisting the locomotive engineer with train operation

- Interacting with dispatchers/roadway workers and others outside the cab

- Dealing with exceptional situations (e.g., diagnosing and responding to train problems)

- $\quad$ Managing Paperwork

The conductor's role in managing the train consist means that the conductor must understand train makeup rules and apply them both in the yard and on the mainline. Experienced conductors understand the implications of car placement and know to take factors like car content (e.g., whether it contains hazardous material), weight and shape, into consideration when building trains in the yard, as well as when setting out or picking up cars during a trip. This knowledge becomes particularly important when faced with unanticipated situations that require removing a train car. In those cases the conductor must understand the implications for reordering the remaining cars to comply with train makeup rules. Conductors must also understand how the train's consist will affect train handling, which is important to ensure locomotive engineer compliance when driving the train.

In the cab, one of the conductor's main tasks is to assist the locomotive engineer while he is operating the train. Conductors handle all radio communication and take care of paperwork when the train is in motion so that the locomotive 
engineer can concentrate on driving the train. The conductor also serves to remind the engineer about upcoming signals and speed restrictions and provides 'look ahead' information to alert the engineer to hills, curves, grade crossings, etc. If the locomotive engineer is not in compliance with the train's operating rules, it is the conductor's responsibility to bring it to the locomotive engineer's attention or, as a final resort, to pull the emergency brake to bring the train to an emergency stop if they feel the train, the train crew, or others outside the train are in danger.

Unexpected situations include anything from train equipment issues, to work en route, to collisions and derailments. Though these unanticipated events run the gamut, train equipment issues are perhaps the most common unanticipated events that arise en route and in these cases it is the conductor who is responsible for troubleshooting and, when possible, repairing the problem.

The conductor is also in charge of all radio communications in the cab. Radio communications come in spurts, meaning there can be lulls in communication and times of heavy interaction that require conductors to multitask. For example, a conductor may need to communicate with the dispatcher (or roadway worker), copy the information back to the dispatcher and write it down, make sure the engineer got the information, and all the while maintain awareness outside the cab, which includes calling out signals and approaches. This can be especially challenging when the dispatcher is speaking quickly and using railroad jargon.

Finally, conductors are required to fill out and maintain all paperwork for the train. While en route, the conductor is responsible for documenting the trip in the conductor's log. This includes writing down slow orders and authorizations from the dispatcher and recording signals as they are passed, as well as filling out other forms as necessary. In addition to maintaining paperwork relating to the trip, the conductor is responsible for staying up to date on the railroad's rulebook, which can be difficult due to the frequency in which operating rules are updated.

\section{Overarching Cognitive Challenges}

Interviews with conductors and trainers revealed a number of complicating situational factors associated with the environment in which train crews operate that challenge cognitive and collaborative performance. These include:

- $\quad$ Large, heterogeneous and dynamically changing territories;

- High risk;

- Unpredictable external conditions (misaligned switches, obstacles on the track, people working on or around the track) requiring sustained vigilance outside the window;

- Workload peaks and demands for multi-tasking;

- $\quad$ Rare events (e.g., equipment malfunctions) that require application of knowledge and skills that are not routinely exercised;
- Actual (or perceived) time pressure;

- Information overload conditions;

- Conditions that contribute to fatigue.

These overarching cognitive challenges place demands on conductor knowledge and long term memory; focus of attention, workload management, effective communication, and decision making.

Interviews with conductors and trainers indicate that it can take up to five years to gain sufficient experience to become a confident, expert conductor with the knowledge and skill to cope with these overarching demands.

The CTA revealed the types of knowledge and cognitive skills that differentiate expert conductors from less experienced ones and enable experienced conductors to better cope with the cognitive and collaborative demands and operate more safely and efficiently:

- Knowledge of the Territory - Knowledge of the territory, including a detailed mental model of the physical territory in which they operate, is critical to enabling train crews to operate efficiently as well as to anticipate and mitigate risks to themselves and others.

- Ability to Maintain Situation Awareness of Surroundings Conductors need to be continuously aware of their surroundings whether they are in the locomotive, switching cars on the ground, or walking to and from the train. They need to maintain awareness of the location of other trains and machines on the track, the location of cars and whether these cars are secured, and the location of people working on or around the track.

- $\quad$ Ability to Project Effect of Consist on Train Dynamics The ability to estimate the impact of consist characteristics (e.g., number of cars, length, weight) on train dynamics is another characteristic conductors develop over time, and an important skill to have to function in their general role of supporting the locomotive engineer.

- Ability to Problem Solve - Conductors are routinely confronted with novel situations where they have to perform mental simulations to identify a correct solution. Building trains and car placement issues, for example, often require problem solving and mental simulation, as do unanticipated, emergency situations.

- $\quad$ Ability to Plan Ahead - Conductors need to project into the future to anticipate and prepare for what is coming up next on the road (e.g., signals, curves, grade crossings, train meets). It is also important to think ahead about various tasks they will need to accomplish over the shift so as to plan the most efficient way to accomplish them.

- Ability to Multi-Task - Another skill that differentiates more experienced from less experienced conductors is the ability to manage multiple demands on attention. Experienced conductors have learned strategies for 
managing and prioritizing these multiple demands on their attention.

- $\quad$ Ability to Exploit External Memory Aids - Mainline operations place heavy demands on memory. Experienced conductors have developed a variety of strategies that rely on external aids to support memory, including strategies to support prospective memory to allow themselves to focus their attention on the task at hand.

- $\quad$ Ability to Foster Shared Situation Awareness through Active Communication - Conductors need to be able to communicate effectively with the locomotive engineer as well as other members of the train crew to maintain shared situation awareness, facilitate efficient work and enhance safety. This communication needs to be an active, ongoing process, beginning with an initial job brief that thoroughly covers potential risks and how they will be mitigated, and continuing on the mainline through active communication such as calling out signals and confirming that the locomotive engineer acknowledged them as well as maintaining shared awareness of each other's location, intentions, and actions (e.g., when the conductor is coordinating work with the Locomotive Engineer from a remote location in the back of the train or on the ground).

In addition to learning about the types of knowledge and skills that enable experienced conductors to perform more safely and efficiently, the CTA also uncovered effects of lack of experience on conductor performance. Less experienced conductors, we found, are less able to handle situations that require balancing multiple demands on attention, they are less able to effectively problem-solve, plan ahead, or identify and avoid potential hazards. Because they have had less first-hand experience on the job, they are typically less confident in their knowledge and ability and less likely to catch and correct problems that may arise.

\section{Training}

The CTA sought to uncover current training practices and trends to help identify future training needs. Currently, there is no conductor training standard or syllabus among railroads for conductor training programs. Training programs generally include a mixture of classroom and on-the-job (OJT) training, though the length of each training type varies by railroad. We found that different railroads have different training models, and the industry is experiencing different training trends among the various railroads.

Our findings point to a need for a more uniform standard of training. Many conductors expressed a desire to standardize OJT, so that guidelines exist for situations and events all conductor trainees must experience in training. Conductors specifically indicated the need to train for rare but serious events and incidents, and stressed the importance of training so that tasks become automated and reflexive (especially in mountain grade territory where the potential for problems and the need for rapid response is greater). Finally, conductors mentioned the need to train new hires to anticipate and discuss risk, and noted that crew resource management training is especially important in giving new hires the confidence to speak candidly with experienced engineers about risks.

\section{KEY FINDINGS}

\section{Locomotive Engineer and Conductor Function As a Joint Cognitive System}

A primary finding of the study is that conductors and locomotive engineers operate as a tightly coupled cooperative team. They function as what is referred to as a Joint Cognitive System in the Cognitive Engineering literature (Woods and Hollnagel, 2006). The phrase Joint Cognitive System is intended to emphasize that conductors and locomotive engineers jointly contribute to the set of cognitive activities required to operate the train safely and efficiently. While each has a distinct set of formal responsibilities, in practice they operate as an integrated team, contributing knowledge and backing each other up as necessary. They not only participate jointly in monitoring outside the window, they participate jointly in planning activities, problem-solving, and identifying and mitigating potential risk.

When operating on the mainline conductors not only serve as a 'second pair of eyes', alerting the locomotive engineer to upcoming signals and potential hazards (e.g., activity at grade crossings; people working on or around the track), they also contribute knowledge and decision-making judgment. Conductors also serve an important, redundant check and backup role, reminding locomotive engineers of upcoming work zones and speed restrictions. If necessary, they will also activate the emergency brake, in cases where the locomotive engineer has not responded quickly enough (whether due to inattention, lack of knowledge, or being incapacitated).

Interestingly, interviews with conductors indicated that locomotive engineers serve an important support role for conductors as well. They help to fill in knowledge gaps, support planning, and help conductors anticipate and mitigate risks. More generally, experienced engineers serve an important mentoring role for less experienced conductors and vice versa.

\section{The Role of Conductors in Handling Unanticipated Situations}

In addition to serving as support and backup for the locomotive engineer, another important role that conductors play on the mainline is to handle unanticipated situations. This includes a variety of situations where conductors need to troubleshoot the source of the problem and take appropriate action. These unanticipated situations impose cognitive as well as physical demands on the conductor. Experienced conductors have developed a variety of skills and strategies that enable them to handle these non-routine situations safely and efficiently. This knowledge is primarily gained in the field through first-hand experience as well as by working with more experienced conductors and Engineers.

\section{IMPLICATIONS OF RESULTS}

The Role of Conductors and Positive Train Control Technology 
One of the questions that motivated the cognitive task analysis was how new technologies, such as positive train control, are likely to impact the role of conductors in the future. The cognitive task analysis addresses this issue by laying out the multiple ways in which conductors contribute to safe and efficient train operations and contrasts this with the anticipated features of positive train control.

Findings from the CTA indicate that positive train control will not provide all of the cognitive support functions the conductor currently provides to the locomotive engineer. For example, conductors support the locomotive engineers in monitoring outside the cab window for potential obstacles and hazards that would not be detected by automated systems, filling knowledge gaps that locomotive engineers may have, and supporting decision-making (e.g., where to stop to avoid blocking a grade crossing).

\section{Potential to Accelerate Development of Expertise}

The results of the CTA suggest an opportunity to potentially accelerate building conductor expertise by providing a broader set of carefully selected experiences as part of on-the-job training. These would enable new conductors to more quickly build up their knowledge of the territory and direct experience with a variety of situations.

The results also point to the importance of teaching conductors and locomotive engineers effective cab communication and job briefing skills (Crew Resource Management, CRM). More focus on effective communication would enhance teamwork and encourage joint problem-solving and decision-making that leverages the knowledge and skills of the entire train crew for safer and more efficient performance.

Finally the results suggest that whenever possible it would be useful to ensure that at least one of the two crewmembers is experienced, particularly over that track. For example, in the case of a locomotive engineer who has never operated over a certain territory, it would be good to pair him with a conductor who has experience with the territory. This not only makes for a safer and more efficient train crew, it also provides opportunities for knowledge transfer between crew members, further accelerating development of expertise.

\section{FUTURE RESEARCH NEEDS}

The cognitive task analysis uncovered several open questions relating to conductor expertise, conductor training, and conductor certification. Future research is needed to answer these questions. For example, while the CTA identified the knowledge and skills required of expert conductors at a high level, additional studies can be performed to examine the cognitive skills at a more detailed level of analysis. Other promising lines for future research relate to how skills expand with level of expertise, how CRM can contribute to safer and more effective teamwork, and the impact of PTC displays on crew cognitive and collaborative processes. Many of these open questions can be explored through the use of simulator studies.
For more information about study methods and results, see Rosenhand, Roth and Multer (forthcoming).

\section{REFERENCES}

Bisantz, A. and Roth, E. M. (2008). Analysis of Cognitive Work. In Deborah A. Boehm-Davis (Ed.) Reviews of Human Factors and Ergonomics Volume 3. Santa Monica, CA: Human Factors and Ergonomics Society. 1-43.

Klein, G. (2010). Macrocogntiive measures for evaluating cognitive work. In Patterson, E. S. and Miller, J. E. (Eds) Macrocognition Metrics and Scenarios: Design and Evaluation for Real World Teams. Burlington, VT: Ashgate Publishing Company.

Klein, D. E., Klein, H. A., Klein, G. (2000). Macrocognition: Linking cognitive psychology and cognitive ergonomics. Proc. 5th Int'l Conf. Human Interactions with Complex Systems, Univ. of Illinois at Urbana-Champaign, 2000, pp. 173-177

Klein, G., Ross, K. G., Moon, B. M., Klein, D. E., Hoffman, R. R. and Hollnagel, E. (2003). Macrocognition. IEEE Intelligent Systems, 18 (3), 81 -85.

Klein, G., Moon, B. and Hoffman, R.F. (2006). Making sense of sense making II: a macrocognitive model. IEEE Intelligent Systems, 21(5), 88-92

Klein, G., Ross, K. G., Moon, B., Klein, D. E., Hoffman, R. R., Hollnagel, E. (2003). Macrocognition. IEEE Intelligent Systems, 81-85.

Patterson, E. S. and Miller, J. E. (2010) Macrocognition Metrics and Scenarios: Design and Evaluation for Real World Teams. Burlington, VT: Ashgate Publishing Company.

Rosenhand, H, Roth, E. M., and Multer, J. Forthcoming. Cognitive and Collaborative Demands of Freight Conductor Activities: Results and Implications of a Cognitive Task Analysis. Washington, D.C.: U.S. Department of Transportation/Federal Railroad Administration.

Roth, E. M. (2008). Uncovering the Requirements of Cognitive Work. Human Factors, 50 (3), 475-480. (Golden Anniversary Special Section on Discoveries and Developments). $\mathrm{http}: / / w w w . i n g e n t a c o n n e c t . c o m /$ content/hfes/hf/2008/00000050/ 00000003/art00022

Roth, E. M., Malsch, N. and Multer, J. (2001). Understanding how train dispatchers manage and control trains: Results of a cognitive task analysis. Washington, D. C.: U. S. Department of Transportation/Federal Railroad Administration. (DOT/FRA/ORD-01/02) Available online at: http://www.fra.dot.gov/downloads/Research/ord0102.pdf

Roth, E. and Multer, J. (2007). Communication and Coordination Demands of Railroad Roadway Worker Activities and Implications for New Technology. U. S. Department of Transportation, Federal Railroad Administration, Office of Research and Development: Washington, D. C. (DOT/FRA/ORD-07/28) Available online at: http://www.fra.dot.gov/downloads/Research/ord0728.pdf

Roth, E. M. and Multer, J. (2009). Technology Implications of a Cognitive Task Analysis for Locomotive Engineers. U. S. Department of Transportation, Federal Railroad Administration, Office of Research and Development: Washington, D. C. (DOT/FRA/ORD-09/03) Available online at: http://www.fra.dot.gov/downloads/Research/ord0903.pdf

Woods, D. D., Dekker, S., Cook, R., Johannesen, L., and Sarter, N. (2010). Behind Human Error. (Second Edition) Burlington, VT: Ashgate Publishing Company.

Woods, D.D. and Hollnagel, E. (2006). Joint Cognitive Systems: Patterns in Cognitive Systems Engineering. Boca Raton, FL: CRC Press. 